\title{
Infant Feeding Challenges Encountered by HIV Positive Mothers in Korogocho Slums, Nairobi, Kenya
}

\author{
Article by Bennadette Mugita Siruri \\ M.Sc Clinical Psychology, Texila American University, Kenya \\ E-mail: bmugita@gmail.com
}

\begin{abstract}
Mother to child transmission of HIV is the major route of HIV infection in children and is responsible for nearly $90 \%$ of childhood infections. International guidelines on infant feeding for HIV- positive mothers promote exclusive replacement feeding (ERF) or exclusive breastfeeding (Laar and Govender, 2013). In spite of these guidelines, poor maternal, infant and young child nutrition (MIYCN) practices are widely documented in Korogocho, with potential detrimental effects on child growth and survival. Rates of exclusive infant feeding, both breast-feeding and formula-feeding, are suboptimal in Korogocho slums with exclusive breastfeeding for the first six months being at about two per cent. (Kimani-Murage et al., 2013). This study was thus carried out with the main objective of assessing the infant feeding challenges of HIV positive mothers in this slum which leads them to practice poor infant feeding. Purposive sampling was used to select the study site and simple random sampling was used to select a sample of 103 calculated using Fischer's method from a target population of 140. Data was collected using interviewer administered questionnaires and three focus group discussions were conducted. Quantitative data was cleaned, coded, entered and analyzed using SPSS Version 16. Qualitative data was analyzed using a three stage thematic approach through transcription of the tape recordings, summarization, thematical description and direct reporting where necessary. Quantitative data was presented in the form of tables and textual summaries. Results from this study showed poor knowledge of appropriate infant methods as only 46 (44.7\%) mothers were satisfied with the infant feeding counseling they had received from the health personnel. Poor clinic attendance by 61(59.2\%) of the mothers may have led to short and few sessions and it also affected the time of infant feeding thus the poor quality of counseling. Most of the mothers were aware of mother to child transmission (MTCT) of HIV through breastfeeding and 62(60.2\%) knew that it could be prevented through exclusive breastfeeding, 60 (58.3\%) through replacement feeding and 54 (52.4\%) through early and abrupt cessation of breastfeeding though quite a number lacked this knowledge. The concerns raised by breastfeeding mothers included; 29(56.9\%) inability to produce sufficient milk, 23 (45.1\%) infections in the baby's mouth, 19 (37.3\%) breast infections and 9(11.8\%) inability to control the feeding due to the influence of the extended family. Feelings of guilt 33(94.3\%) and cost of replacement feeding 26(74.3\%) were the major concerns among replacement feeding mothers. Though 17 (16.5\%) had ceased breastfeeding early, up to 15(88.2\%) of them lacked advice on the appropriate feeding methods after breastfeeding cessation. Mothers in this study were aware of the WHO recommendations on infant feeding and MTCT through breastfeeding and its prevention. However, they faced several challenges which include poor knowledge on appropriate infant feeding methods, inability to produce sufficient milk, high cost of replacement food and lack of knowledge on appropriate infant feeding practices after cessation of breastfeeding. More emphasis should be put on proper clinic attendance by the mothers as this will provide additional time for the health personnel to provide full information infant feeding. Provision of information on appropriate infant feeding practices after cessation of breastfeeding should be enhanced. Further investigations are required to determine the cause of insufficient milk production by the mothers.
\end{abstract}


Texila International Journal of Public Health

Volume 4, Issue 4, Dec 2016

\section{Abbreviations}

$\begin{array}{ll}\text { AFASS } & \text { Acceptable, Feasible, Affordable, Sustainable, Safe } \\ \text { AIDS } & \text { Acquired Immunodeficiency syndrome } \\ \text { ANC } & \text { Antenatal clinic } \\ \text { ARVs } & \text { Antiretroviral drugs } \\ \text { DMOH } & \text { District Medical Officer of Health } \\ \text { ERF } & \text { Exclusive replacement feeding } \\ \text { HIV } & \text { Human Immunodeficiency Virus } \\ \text { MIYCN } & \text { Maternal, infant and young child nutrition } \\ \text { MTCT } & \text { Mother to Child Transmission } \\ \text { NASCOP } & \text { National AIDS Control Programme } \\ \text { PMTCT } & \text { Prevention of Mother to Child Transmission } \\ \text { SPSS } & \text { Statistical Package for Social Sciences } \\ \text { UNAIDS } & \text { Joint United Nations Programme on HIV/AIDS } \\ \text { UNICEF } & \text { United Nations Children's Fund } \\ \text { UNFPA } & \text { United Nations Population Fund } \\ \text { VCT Voluntary Counseling and Testing } \\ \text { WHO World Health Organization }\end{array}$

\section{Definition of terms}

Acceptability: Ability of a mother to cope with the problem of not breastfeeding and resisting pressure from friends and relatives to breastfeed.

Affordability: Ability to pay for the ingredients, fuel, water and other equipment needed for replacement feeding.

Appropriate: A feeding method that is suitable or proper in the mother's circumstances

Challenges: These are any difficulties faced by the HIV positive mothers in their efforts to effect their infant feeding options.

Exclusive Breast-Feeding: A child is fed with only breast milk and no other foods or liquids by mouth (except for medicine) for the duration specified. Exclusive Replacement feeding: A child does not receive any breast milk in addition to replacement foods for the duration specified.

Feasibility: Ability of a mother who chooses replacement feeding to have adequate time, knowledge, skills and other resources to prepare the replacement food and feed her baby up to twelve times in 24 hours.

Focus group: A focus group is a small-group discussion guided by a trained leader which is used to learn more about opinions on a designated topic, and then to guide future action.

Knowledge: A familiarity, awareness or understanding of something in this context the appropriate infant feeding methods.

Mixed feeding: This is defined here as the consumption of other non breast milk products in conjunction with breastfeeding.

Safety: Replacement food should be nutritionally sound and free from germs. The water it is mixed with should be boiled, and utensils should be cleaned (preferably boiled) before each use. This means the mother must have access to a reliable supply of safe water and fuel.

Slum: A run down area of a city usually inhabited by the very poor or socially disadvantaged, characterized by urban decay, high rates of poverty, unemployment, substandard housing and poor sanitation including lack of clean water and social facilities.

Sustainability: Ability to obtain a constant supply of formula feed for the first six months of life and regular access to water without even a brief disruption. 


\section{Introduction}

\section{Background information}

The epidemic of mother to child transmission (MTCT) of Human Immunodeficiency Virus (HIV) in resource poor countries is dramatic and is responsible for nearly $90 \%$ of childhood infections. According to UNAIDS update for 2011, there were about 34 million people living with HIV worldwide (UNAIDS, 2011). Sub Saharan Africa still bears the largest share of the global HIV burden as 68\% of those living with HIV live in Sub-Saharan Africa and more women than men are HIV positive (UNAIDS, 2010). In 2010, an estimated 3,400,000 children aged less than 15 years were living with HIV in the world (WHO, 2011) and around 330,000 children were newly infected in that year alone with an estimated 230,000 dying from AIDS (UNAIDS, 2012). Without intervention to prevent mother-to-child transmission of HIV, 30-45\% of infants born to HIV positive mothers in developing countries become infected during pregnancy, delivery and breastfeeding (Muluyeet al., 2012).

Breastfeeding carries significant health benefits to infants and young children (WHO, 2007) and for several decades the promotion of exclusive breastfeeding in resource poor settings has played a critical role in improving child health by providing optimum nutrition and protection against childhood infections (Suryavanshi et al., 2003) Unfortunately, the documentation of the risk of HIV transmission through mother's milk has rendered infant feeding choice a most exigent issue and has created considerable uncertainty and fear among HIV-positive child bearing women (Leshabari et al., 2006). The HIV epidemic has challenged health systems and public health programs throughout the world. Balancing the risks of HIV transmission during breast-feeding with the risks of not breast-feeding, in settings where access to safe replacement foods, health care, and support are limited, is one of the most difficult issues facing HIV-affected families today (Piwoz and Bentley, 2005). This has resulted in a painful dilemma for millions of women in developing countries especially those in resource poor settings for whom there are no easy options (Leshabari et al., 2006).

For HIV positive women in well-resourced countries, the advice from national health agencies is to avoid breastfeeding all together because the risk of HIV transmission far outweighs the risks associated with replacement feeding. (WHO, 2003). However in Korogocho slum which is resource poor, where access to safe replacement foods, health care, and support are limited and where infectious diseases and malnutrition are the major causes of childhood death (Wikipedia, 2013), replacement feeding can be much more hazardous. Balancing the risks of HIV transmission during breast-feeding with the risks of not breastfeeding is one of the most difficult issues facing HIV-affected families in this slum. This has resulted in a painful dilemma for the HIV positive mothers there.

The national and international guidelines on HIV and infant feeding are, by definition meant to provide infant feeding recommendations in general terms. They are thus not immediately relevant or appropriate on the local level unless, as explicitly spelt out by WHO, they are adapted to the particular social and cultural context in which women make their choices of infant feeding method (Leshabari et al., 2006). This study explored HIV-positive women's infant feeding challenges encountered in trying to implement their feeding of choice in the social and cultural context of Korogocho slums in Nairobi, Kenya.

\section{Problem statement}

Infant feeding is a crucial factor in determining growth and development of a child. For infants, breastfeeding is without question the best way to be fed (WHO, 2007). However, the risk of HIV transmission from mothers to their infants during breastfeeding poses a dilemma for infant feeding in Korogocho slum. This is because Korogocho is resource poor and is experiencing an HIV/AIDS epidemic of devastating magnitude with a prevalence of $14 \%$ compared to the national 7.8\% with women bearing the brunt both of poverty and HIV/AIDS (Wikipedia, 2013). Alongside poverty, unemployment, crime and other social ills, this epidemic continues to be one of the biggest problems facing HIV positive mothers in 
Texila International Journal of Public Health

Volume 4, Issue 4, Dec 2016

Korogocho slums today. Poor hygiene prevalent in the slum has resulted to the rapid spread of cholera, malaria, typhoid, dysentery, and water and air borne diseases. In spite of the WHO recommendations on infant feeding, poor maternal, infant and young child nutrition (MIYCN) practices are widely documented in Korogocho, with potential detrimental effects on child growth and survival. Both clinical trials and evaluations of PMTCT programs have found that rates of exclusive infant feeding, both breast-feeding and formula-feeding, are suboptimal here. Kimani- Murage and colleagues (2013) in their study in Korogocho on infant feeding practices reported that infant feeding practices were poor and exclusive breastfeeding for the first six months was only about two per cent. This makes the practical application of the WHO recommendations in the operational setting of Korogocho slum a difficult issue. So far no documentation has been done on the infant feeding challenges encountered by HIV positive mothers in Korogocho slums both for exclusive breastfeeding and replacement feeding. The aim of this study was to establish these challenges by HIV positive mothers in this set up which could be leading to the poor infant feeding practices. The results of this study will inform design of interventions aimed at improving infant feeding practices in urban poor settings in Nairobi, Kenya.

\section{Justification}

The current WHO recommendations are that HIV positive mothers should exclusively breast feed followed by early cessation or replacement feed if they can meet the AFASS criteria for replacement feeding. However it seems that many mothers in Korogocho are having problems in following these guidelines as poor infant feeding practices have been documented. This study aimed at finding out from the mothers the challenges that they face in acquiring knowledge on appropriate infant feeding methods, challenges of exclusive breastfeeding, early breastfeeding cessation and replacement feeding and their awareness on MTCT of HIV through breastfeeding and its prevention. Once these are known, they will assist in strengthening the information, education and communication materials used in PMTCT programs. The findings will also help in informing policies that will target the community on PMTCT through breastfeeding.

\section{Objectives}

\section{Broad objective}

To assess the infant feeding challenges encountered by HIV positive mothers in Korogocho slums, Nairobi, Kenya.

\section{Specific Objectives}

1. To determine the challenges of acquiring knowledge on the appropriate infant feeding methods in Korogocho slums, Nairobi, Kenya.

2. To determine the HIV positive mothers' awareness of MTCT of HIV through breastfeeding in Korogocho slums, Nairobi, Kenya.

3. To determine the challenges faced by HIV positive mothers who practice exclusive breastfeeding and replacement feeding in Korogocho slums, Nairobi, Kenya.

4. To identify the challenges to early and abrupt cessation of breastfeeding in Korogocho slums, Nairobi, Kenya.

\section{Research questions}

1. What are the challenges of acquiring knowledge on the appropriate infant feeding methods in Korogocho slums, Nairobi, Kenya?

2. What is the awareness of MTCT of HIV through breastfeeding among HIV positive mothers in Korogocho slums, Nairobi, Kenya?

3. What are the challenges faced by HIV positive women who practice exclusive breastfeeding and replacement feeding in Korogocho slums, Nairobi, Kenya? 
4. What are the challenges of early and abrupt cessation of breastfeeding in Korogocho slums, Nairobi, Kenya?

\section{Conceptual framework}

Based on the literature review, the following diagrammatic concepts have been identified and put in conceptual framework. They illustrate theoretical relationship between background, proximate and outcome factors. The conceptual framework identified an outcome variable infant feeding challenges which was the main focus in this study. Infant feeding challenges was the dependent variable whereas socio demographic and cultural factors were the independent variables with knowledge on appropriate feeding methods and practices being the proximate factors.

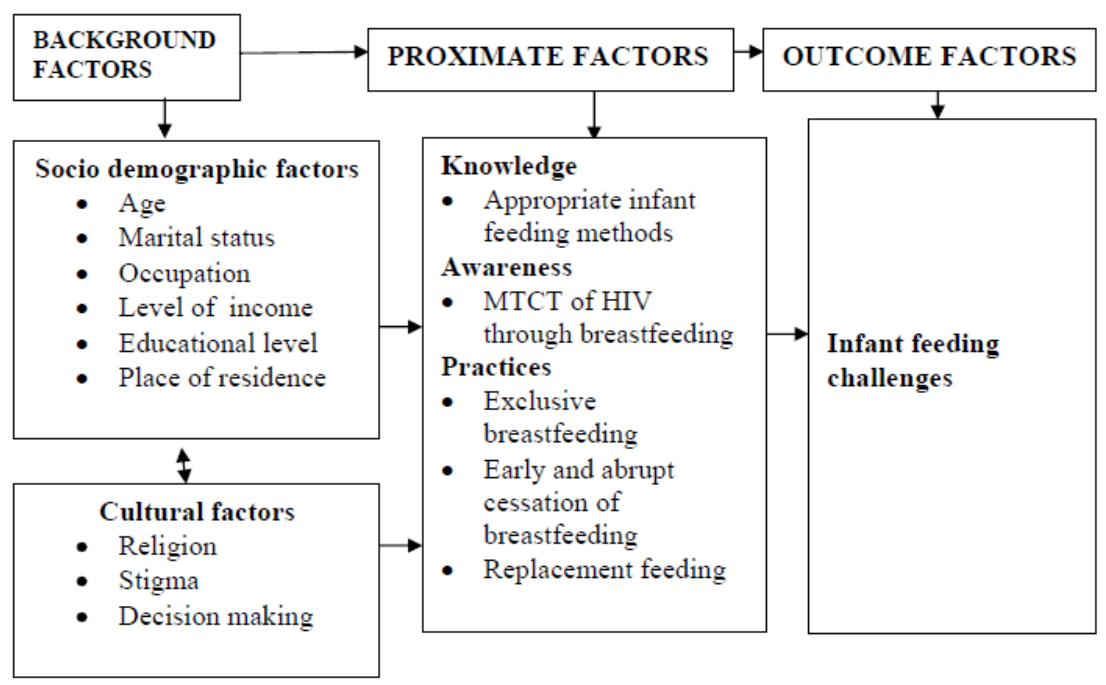

Figure 1.1 Conceptual Framework

\section{Explanation of the framework}

\section{Socio-demographic factors}

The risk of serious mortality and the disadvantages of artificial feeding are increased in poor households with inadequate sanitation, unsafe and scarce water supplies, no refrigeration, poor health services and little knowledge of hygiene. The person who provides for the family has an influence on how the respondent spends finances and so also indirectly on the feeding choice she makes. Literacy level is generally low among women and lack of education is compounded by misconceptions about HIV infections. These misconceptions lead to underestimation of interventions put in place to curb HIV spread such as appropriate infant feeding (Alcala, 2005).

\section{Knowledge on appropriate infant feeding methods}

Mothers with no counseling or poor quality counseling on feeding methods have an increased risk of transmitting HIV to their children (Chopra et al., 2005). One of the major challenges facing women in adopting and adhering to current recommendations is lack of access to good quality information.

\section{Literature review}

\section{Introduction}

The HIV epidemic has placed a strain on health systems and public health programs throughout the world. However, balancing the risks of HIV transmission during breastfeeding with the risks of not breast-feeding in settings where access to safe replacement foods, health care and support are limited is one of the most difficult issues facing HIVaffected families today (Suryavanshi et al., 2003). International guidelines on infant feeding 
for HIV-positive mothers promote Exclusive Replacement Feeding (ERF) (infant formula or animal milk) or exclusive breastfeeding (with no supplements of any kind) (Engebretsen et al., 2010). A mixed feeding pattern, where breastfeeding is combined with other milks, liquid foods or solids, has been shown to increase the risk of transmission of HIV and is strongly discouraged (Laar and Govender, 2013). Replacement feeding is only recommended if it is acceptable, feasible, affordable, sustainable and safe (AFASS). If not, exclusive breastfeeding is recommended during the first months of the baby's life" (Engebretsen et al., 2010,). To minimize HIV transmission risk, breastfeeding should be discontinued as soon as feasible, taking into account local circumstances, the individual woman's situation and the risks of replacement feeding including infections other than HIV and malnutrition (WHO, 2003a).

For HIV positive women in well-resourced countries, the advice from national health agencies is to avoid breastfeeding all together because the risk of HIV transmission far outweighs the risks associated with replacement feeding. In countries with fewer resources where replacement feeding can be much more hazardous, the recommendation for infant feeding usually depends on a mother's individual situation. This means that a mother should be advised to give replacement foods instead depending on personal circumstances (Omari et al., 2003). The AFASS of diverse alternatives to breastfeeding have been tried out including replacement feeding with modified animal milk or infant formula, wet nursing and expressed and heat treated breast milk (Rollins et al., 2004). However, the superiority of breastfeeding in reducing child morbidity and mortality is unquestionable, as it greatly reduces the risks of enteric infection and of defective nutrition, particularly in resource-poor settings (Bhandari et al., 2003). Hence, in recommending an infant feeding method to HIV-positive women, the risks implied in breastfeeding must be carefully balanced with the competing risks of not breastfeeding (Kuhn et al., 2004).

\section{Challenges of acquiring knowledge on the appropriate infant feeding methods}

In Sub-Saharan Africa, the issue of HIV transmission through breastfeeding is of public health importance particularly in countries where HIV affects significant proportion of the population and where breastfeeding is the cultural norm (UNAIDS, 2012). Studies have confirmed that about a third of HIV transmission from mother to child occurs through breastfeeding (Burr, 2011). This is as a result of inappropriate infant feeding practices. According to WHO, appropriate feeding practices play a crucial role in preventing mortality and in achieving optimal health outcomes for infants and young children during the first 6 months of life (WHO, 2012).

Infant feeding counseling based on international guidelines is considered a basis in the prevention of MTCT of HIV in Sub-Saharan Africa (Laar and Govender, 2013). According to WHO, appropriate feeding practices play a crucial role in preventing mortality and in achieving optimal health outcomes for infants and young children during the first 6 months of life (WHO, 2011). Counseling HIV positive mothers on safer infant feeding options is an important component of programs to prevent MTCT of HIV (Ketepa et al., 2011, WHO, 2003). Health services must offer women counseling, guidance and support to enable them make informed choices (Desclaux et al., 2009). Chopra and colleagues (2005) report that counseling is central to preparing mothers for making a proper informed choice about adequate feeding practices to prevent their infants from acquiring HIV infection. To help HIV-positive mothers make the best infant feeding choice, they should receive appropriate counseling that includes information about the risks and benefits of various infant feeding options based on local assessments, and guidance in selecting the most suitable option for their own situation. Counseling, information provision and support during the antenatal period is key for women to make informed choices. Postnatal follow-up is also crucial to this support, as is nutritional counseling, particularly around the period of breastfeeding cessation (WHO, 2007). According to Ehrnst and Zetterstrm (2005), the recommendations given and the way in which counseling is performed are the most important determinants of a mother's decision about how to feed her infant. Antenatal counseling needs to prepare mothers for 
common challenges during the postpartum period and especially for resisting family pressures and dealing with perceived milk insufficiency. In addition, postpartum maternal and child health services need to be structured, and health workers need to be trained to support these women after birth in maintaining their infant-feeding choice and to assist them through difficult transition periods (Dohertyet al., 2006b). Access to information and improved interpersonal communication and counseling are among many factors influencing an HIV positive mother's confidence, courage and ability to select and successfully implement the most appropriate feeding option given her own individual situation (Leshabari et al., 2007)

Lack of good quality information on infant feeding is one of the major barriers to adopting and adhering to current WHO recommendations on infant feeding and mothers with no counseling or poor quality counseling on feeding methods have an increased risk of transmitting HIV to their children (Chopra et al., 2005). Good quality pre, peri and postnatal counseling have been found to increase exclusive breastfeeding prevalence (Aidam et al., 2005).

Though studies have in different regions have documented infant feeding practices, so far no documentation has been done from Korogocho slums on challenges of acquiring knowledge on appropriate infant feeding methods hence the need for this study to establish these challenges.

\section{Awareness of HIV positive mothers on MTCT of HIV through breastfeeding}

Mother-to-child transmission (MTCT) of HIV infection remains a major public health problem and constitutes the most important cause of HIV infection in children under the age of 15 years old (UNAIDS, 2012). In 2012, 260,000 children acquired HIV infection in low and middle income countries and more than $90 \%$ of the newly HIV infected children lived in Sub-Saharan Africa, home to 92\% of pregnant women living with HIV (UNAIDS, 2013). In 2008, the adult HIV prevalence in Korogocho slums was 14\% (Wikipedia, 2013). Awareness on MTCT of HIV and knowledge of its timing usually pose a direct effect on utilization of PMTCT services (mainly HIV testing, infant feeding options and antiretroviral use (Asefa and Beyene, 2013). The objective of this study is to assess the awareness of HIV positive mothers in Korogocho slums about mother to child transmission of HIV through breastfeeding as this has not yet been documented.

\section{Challenges of exclusive breastfeeding and replacement feeding}

\section{Challenges of exclusive breastfeeding}

Breastfeeding is the norm in most cultures and is the best food for infants. It is an effective method of reducing the risk of common childhood morbidity, particularly gastrointestinal and respiratory infections, and of promoting child survival and maternal health through child spacing (WHO, 2007). The transmission of HIV through breast milk is a critical public health problem that is complicated by the fact that replacement feeding is known to lead to increased mortality risks, particularly in resource poor settings. In Africa, one third to a half of infant HIV infections are due to breastfeeding. If an HIV positive mother chooses to breastfeed, then there are several things she can do to lower the chances of her baby getting infected. The first of these is exclusive breastfeeding since studies have shown that mixed feeding substantially increases the chances of HIV transmission and death (Leroy et al., 2003; Coutsoudis et al., 2005; Iliff et al., 2005). This has indeed raised hopes that MTCT can be reduced where breastfeeding is culturally normative since breast milk provides all the fluids and nutrients that a young baby requires, so even water can and should be avoided (Suryavanshi et al., 2003). In view of these findings, it was suggested that the more strictly HIV positive mothers are able to breastfeed exclusively, the lower the risks of HIV infection and death in their infants (Iliff et al., 2005).

Though breastfeeding by HIV-positive women is a major means of HIV transmission, not breastfeeding carries significant health risks to infants and young children (UNICEF, 2012). Exclusive breastfeeding is an important component of child survival and prevention of 
Texila International Journal of Public Health

Volume 4, Issue 4, Dec 2016

mother-to-child transmission of HIV in resource-poor settings. In addition, EBF carries a 4-10 fold decreased risk of mother-to-child transmission (MTCT) of HIV compared to mixed feeding during the infant's first six months of life (Kafulafulaet al., 2013). It is a healthful behavior for HIV-exposed infants and their mothers, is helpful for birth spacing, requires minimal preparation, is not dependent upon outside materials, and breast milk does not need to be purchased. Additionally, the fact that breastfeeding is a common behavior means it is unlikely to flag the mother's HIV status (Younget al., 2011). However, current rates of EBF are well below targeted levels in both HIV-affected and unaffected populations around the world though increasing rates of EBF is one of the most powerful interventions to save child lives; the promotionof breastfeeding could prevent 13-15\% of child deaths in low-income countries (Young et al., 2011, Laar and Govender, 2013). Exclusive breastfeeding is, however rare, while early mixed feeding is common. (Becquet et al., 2005b; Coutsoudis, 2005, UNICEF, 2012). In fact, exclusive breastfeeding has been noted to be an alien concept in most African cultures, the prevailing form of breastfeeding worldwide being mixed breastfeeding. A study in Cote d'Ivoire also reported that exclusive breastfeeding was not practiced, since all women who participated in this study had given water to their children starting one day after birth (Becquet et al., 2005a). Poor breastfeeding practices are widely documented in developing countries including Kenya. For example in Kenya, only a third of children are exclusively breastfed for six months. Poor breastfeeding practices are particularly a problem in the urban slums, where most urban residents in Kenya live. According to a study by Kimani-Murage and colleagues (2013) in Korogocho only two percent of infants were exclusively breastfed for six months, hence the need for this study to determine the challenges that the mothers in Korogocho are having with exclusive breastfeeding.

\section{Challenges of exclusive replacement feeding}

Over the last several decades, the promotion of exclusive breastfeeding in resource poor settings has played a critical role in improving child health by providing optimum nutrition and protection against childhood infections (Suryavanshi et al., 2003). However, the documentation of breastfeeding as a source of HIV infection in babies born to HIV positive mothers represents a public health dilemma. The transmission of HIV through breast milk is a critical public health problem that is complicated by the fact that breastfeeding is a cultural norm and that replacement feeding is known to lead to increased mortality risks, particularly in resource poor settings (Dohertyet al, 2006a). In Africa, one third to a half of infant HIV infections are due to breastfeeding. Replacement feeding is the only $100 \%$ effective way to prevent mother-to-child transmission of HIV after birth, but the risk of infant mortality from other illnesses such as diarrhoea must be taken into account (Mnongya, 2013). As knowledge about the risk of HIV transmission through breastfeeding has reached health care workers, the general population, and individual mothers, uncertainty has developed on how best to feed infants in the context of HIV. Women who know or suspect they are HIV positive are faced with difficult and complex choices (Leshabari et al., 2006).

International guidelines on infant feeding for HIV positive mothers promote replacement feeding or exclusive breastfeeding (WHO, 2003). However, in countries where breastfeeding is the norm, formula feeding has been noted to alert a woman's family or community that she is HIV-positive, and may result in stigma or other negative repercussions (de Paoli et al., 2002). Most studies of choice of infant feeding method show that while HIV-positive women commonly make a distinct choice to exclusively breastfeed or exclusively replacement feed during pregnancy, they often end up practicing mixed feeding early in the baby's life (KonizBooher, 2004; Thairu et al., 2005).

Shapiro and colleagues in their study in Botswana where formula feeding in HIV-positive women is strongly encouraged and offered free of charge in PMTCT programmes, concluded that adherence to exclusive replacement feeding was sub-optimal and potentially over reported (Shapiro et al., 2003). A study in Zambia similarly reported that HIV positive women changed to mixed feeding very early, whether they started out with replacement 
feeding or exclusive breastfeeding (Omari et al., 2003). Similar results were reported from a study carried out in Korogocho Slum which found that mixed feeding was the norm and replacement feeding was minimally practiced among the HIV positive mothers (KimaniMurage et al., 2013). No documentation though has been done on those challenges that these mothers who opt for replacement feeding face in their day to day practice of replacement feeding, hence this study was carried out in order to help answer that.

\section{Challenges of early and abrupt cessation of breastfeeding}

The longer an HIV positive mother breastfeeds the more likely she is to infect her baby (UNICEF, 2012). For this reason, international guidelines have indicated that exclusive breastfeeding should be accompanied by early and abrupt cessation of breastfeeding. But according to a WHO consensus statement: "At six months, if replacement feeding is still not acceptable, feasible, affordable, sustainable and safe, continuation of breastfeeding with additional complementary foods is recommended, while the mother and baby continue to be regularly assessed (Thairu et al, 2005). Thus, all breastfeeding should only be discontinued as soon as it is feasible, once a nutritionally adequate and safe diet without breast milk can be provided. This should take account of the local circumstances, the individual woman's situation and the risks of replacement feeding (WHO, 2006). In order to guide health workers in assisting women to make appropriate infant feeding choices, WHO and UNICEF developed the Global Strategy for Infant and Young Child Feeding (WHO, 2003). The recommendation for women known to be HIV positive is avoidance of all breastfeeding if replacement feeding is acceptable, feasible, affordable, sustainable and safe. Otherwise exclusive breastfeeding for the first months of life is recommended, and should be discontinued as soon as it is feasible, when conditions for safe replacement feeding can be met (WHO, 2010).

Studies in Zimbabwe (Iliff et al., 2005), West Africa (Leroy et al., 2003), South Africa (Coutsoudis et al., 2001), and Tanzania (Fawzi et al., 2002) showed that more than two-thirds of all postnatal transmission occurs after the first six months of the baby's life. This provides a strong justification for supporting early breastfeeding cessation among HIV positive women. However, some studies have reported that many women have difficulty breastfeeding exclusively or weaning their children early (Coutsoudis, 2005). Although there are studies documenting successful cessation of breastfeeding, for example in the Cote d'Ivoire study (Becquet et al., 2005b), the cultural inclination toward prolonged breastfeeding patterns in sub-Saharan Africa in general makes early cessation difficult (de Paoli et al., 2001; Shapiro et al., 2003 ). Hence, several studies in diverse contexts have documented poor adherence to the recommended feeding methods (de Paoli et al., 2002; Omari et al., 2003), but there is limited evidence regarding why this is so. No documentation has been done so far concerning challenges of breastfeeding cessation among HIV positive mothers in Korogocho slums, hence the need for this study to establish the same.

\section{Methodology}

\section{Study site}

The study was carried out in Korogocho one of the largest slums in Nairobi (http://www.begakwabega.com/Korogocho-eng.html, GOK, 2009). Home to 150,000 to 200,000 people pressed into a 1.5 square kilometres, northeast of the city centre, Korogocho is an illegal settlement founded in the early eighties as a shanty town on the then outskirts of the city (GOK, 2009, http://stjohnssportssociety.weebly.com/about-us.html). Over half of the land is state property and the rest is privately owned (http://www.begakwabega.com/Korogocho-eng.html, GOK, 2009). It borders the largest dumping site in Nairobi - the Dandora dumping site - posing environmental health and security risk for the residents and surrounding settlements. With poor infrastructure, few resources, overcrowding, and proximity to the dump, health in Korogocho is poor (Wikipedia, 2013). The area has been singled out by officials because of high illegal drug and alcohol 
Texila International Journal of Public Health

Volume 4, Issue 4, Dec 2016

abuse. Like any of the other slum settlements in Nairobi, it has a large poor population with no access to minimum services, living largely in structures made out of temporary and recycled building materials - or made out of timber, mud walling, and roofing made up of substandard materials such as sacks, carton paper and polythene (http://stjohnssportssociety.weebly.com/about-us.html) There is no Proper sanitation and waste management. Water reticulation is limited and the road network is inadequate (GOK, 2009). The chief and the administration police have a permanent residence at the centre of Korogocho Village. The structures in Korogocho are very congested with an average of 5-6 persons per room and its socio-economic reality is very poor. There are no public services and the absence of the state is keenly felt. There are two city council schools with over 4,000 children and many other informal private schools which are insufficient (Wikipedia, 2013). Over $70 \%$ of the Korogocho population is less than 30 years of age and unemployment rates are high with majority of those employed working as casual workers in the formal sector industries (GOK, 2009). There are 4 health centers present in Korogocho which include Tumaini, Provide International, Vision Clinic and Kariobangi Health Centre but none operates on 24-hr basis the nearest such is Kariobangi Health Centre. There is no central sewer system and crime rates are high (http://stjohnssportssociety.weebly.com/about-us.html). With poor infrastructure, few resources, overcrowding, and proximity to the dump, health in Korogocho is poor (Wikipedia, 2013). Though the slum is supplied with water most pipes run on the surface thus risking contamination in case of leakages. Not all houses though are served by this water but some rely on water vendors or buy at some water points within the settlement (http://stjohnssportssociety.weebly.com/about-us.html). The slum is bordered to the south by Nairobi River which is heavily polluted from upstream as well as from dumping from within. There are a few communal toilets and bathrooms some of which are rundown and not functional at all and most of them are not connected to a sewer line. There are many uncovered foul drainage systems leading to mixing of clean water and foul water. Poor hygiene in the slum results to the rapid spread of typhoid, dysentery, water and air borne diseases. Sexually transmitted diseases and HIV/AIDS are also widespread. According to clinical reports from Kariobangi health centre, the leading causes of child morbidity are diarrhoeal diseases, upper and lower respiratory tract infections the commonest being pneumonia and tuberculosis (Nikolaj, 2005).

\section{Study population}

The study subjects were enrolled from a target population of 140 HIV positive postnatal mothers who had children aged between aged 6 weeks to 6 months when exclusive breastfeeding is most emphasized and enrolled in the Kariobangi Health Centre PMTCT Programme. The lower age limit of 18 years was used because they could give informed consent with the upper of 49 years being the maximum child bearing age.

\section{Inclusion criteria}

- Post-natal women aged 18-49 years

- Having children aged 6 weeks to 6 months

- HIV positive

- Consent to participate in the study

- Residents of Korogocho slum

- Enrolled in the Kariobangi health Centre PMTCT programme

- Mothers must be practicing exclusive breastfeeding, replacement feeding or early and abrupt cessation of breastfeeding.

\section{Exclusion criteria}

- Having children older than six months

- Unwillingness to participate in the study

- Not attending PMTCT programme 
- $\quad$ Not aged between 18 and 49 years

- HIV negative

- Not residents of Korogocho slums

- Practicing mixed feeding

\section{Study design}

This was a cross-sectional descriptive study design with quantitative closed-ended questions and qualitative approach with open-ended questions in primary data collection. A cross-sectional design was used because it maximized the reliability of the data collected and data was collected quickly and inexpensively compared to other research designs. In addition, the characteristics of the variables being measured could not have changed much due to the short period of data collection. Data was collected using a structured questionnaire which included basic socio-demographic indices, challenges of acquiring knowledge on appropriate infant feeding methods and challenges encountered by the exclusive breastfeeding mothers, replacement feeding mothers and those who had ceased breastfeeding early. The qualitative components of the research were FGDs which took an exploratory and descriptive approach which was useful in determining what proportion of mothers had a certain opinion. The researcher opted for this method since interaction of group members would stimulate richer responses and allow new and valuable thoughts to emerge. It also provided details that were difficult to obtain using quantitative methods. Using both methods complemented each other as qualitative methods provided in-depth information while quantitative methods provided data which answers questions (Mugenda and Mugenda, 1999)

\section{Sample size determination}

The required sample size was calculated using the Fischer at al. (1983) method for calculating sample size as quoted in Mugenda and Mugenda (1999).

Sample size $n=\left(z^{2} p q\right) / d^{2}$ where;

$\mathrm{n}=$ desired sample size

$\mathrm{z}$ = standard normal deviate at the required confidence level

$\mathrm{p}=$ is the proportion of mothers who are HIV positive. HIV prevalence among the

general population is $14 \%$ but the prevalence among women aged 18-49 years is

undocumented. In this case, $p$ is used as $50 \%$ to achieve the maximum sample size.

$\mathrm{q}=1-\mathrm{p}$

$\mathrm{d}=$ level of statistical significance set

Therefore at 95\% confidence interval

$$
\begin{aligned}
& \mathrm{n}=\frac{\left(1.96^{2} \times 0.5 \times 0.5\right)}{0.05^{2}} \\
& =\frac{0.9604}{0.0025} \\
& \mathrm{n}=385
\end{aligned}
$$

Since the population was below 10,000 the adjusted sample size (nf) will be; $\mathrm{nf}=\mathrm{Nn} / \mathrm{N}+\mathrm{n}$ where;

$\mathrm{nf}=$ desired sample size when population is less than 10,000

$\mathrm{n}=$ desired sample size when population is more than 10,000

$\mathrm{N}=$ estimate of the population size

Therefore at $95 \%$ confidence interval

$$
\begin{aligned}
& =\frac{385 \times 140}{385+140} \\
= & \frac{53900}{525} \\
\text { nf } & =103
\end{aligned}
$$

The sample size was calculated to be103 using the above formula. 
Texila International Journal of Public Health

Volume 4, Issue 4, Dec 2016

\section{Data collection tools}

For this study pre-tested structured questionnaires and focus group discussion guides were used for data collection. The tools were designed after an in-depth literature review and according to the objectives of the study. The questionnaire consisted of questions regarding socio-demographic profile of the mothers, challenges encountered by the HIV positive mothers in acquiring information on the appropriate infant feeding methods, challenges of exclusive breastfeeding, replacement feeding and early and abrupt cessation of breastfeeding. A focus group discussion guide was also developed to gain more insight into the mothers' infant feeding challenges. The focus group discussion guide consisted of questions that covered the same topics as the questionnaire.

\section{Recruitment and training of research assistants}

Four research assistants were trained from Kariobangi Health Centre. Training was on the aims and objectives of the study and the data collection tools. They were trained on how to conduct interviews and focus group discussions.

\section{Pre-testing of questionnaires}

This was used to refine the questionnaire design and identify errors which may only be apparent to the population concerned for example the meaning of words. The pre-test sample was similar to the trial group and took place in conditions similar to those of the actual questionnaire administration. This questionnaire was pilot tested with ten mothers who were not included in the study.

\section{Sampling techniques}

The study site was purposively selected because it is a slum whose inhabitants are poor, majority of the population are young, and it had a high HIV prevalence of HIV. Thereafter, simple random sampling was used to select the actual participants. Simple random sampling is a one stage probability sampling procedure in which members of a population are selected one at a time without a chance of being selected again until the desired sample size is obtained (Mugenda and Mugenda, 1999). Simple random sampling was considered adequate as each mother had a chance of being selected. Sampling was done by numbering all 140 target mothers using a table of random numbers. The starting point in the table was determined by randomly picking a page and dropping a finger on the page with eyes closed. The numbers were chosen up and down till all the 103 required sample size was obtained. Once a number was chosen it was not chosen again. A list of mothers was obtained from the clinic records. Mothers who attended the support group on Tuesdays and consented also participated in the FGDs.

\section{Data collection}

Focus group discussions (FGD'S) guides and structured questionnaires were used for data collection of the sampled respondents who gave consent. Four research assistants assisted in collecting the data. The interviews were conducted in Kiswahili since some respondents could not understand English. Three FGDs were conducted and the groups were chosen from the HIV positive mothers who were enrolled in the Kariobangi Health Centre PMTCT programme, registered with the support group and had infants aged between aged 6 weeks to 6 months. Each FGD consisted of 8 mothers, a note taker, a facilitator and the researcher. The focus group discussions were done on consecutive Tuesday afternoons when the mothers attended the support group. Eight mothers per group sat around a table with the researcher, a facilitator, and a note taker. The focus group discussion started with an introduction of the facilitator, the researcher, the note taker, the participants, the procedures during the discussion and an ice- breaker question to put participants at ease. The discussion topics included questions about the challenges of acquiring knowledge on appropriate infant feeding methods, and challenges faced by HIV positive mothers who practiced exclusive breastfeeding, 
exclusive replacement feeding and early cessation of breastfeeding. The facilitator translated the focus group questions to the respondents. The focus group discussions were recorded in a written format as well as on tape and the correctness of responses was checked and confirmed immediately after the discussions. Each focus group discussion lasted for approximately one and half hours. The questionnaires were filled while the mothers were in the post natal clinic and the researcher was present during the interviews. To ensure reliability, the researcher supervised all aspects of data collection and checked questionnaires for correctness and completeness immediately after completion.

\section{Data analysis and presentation}

Data analysis for the focus group discussions was conducted manually without use of a software program. Immediately after the discussion, all audio taped interviews were transcribed verbatim, and translated into English. These transcriptions and the notes from the note taker were reviewed and double-checked for consistency and accuracy by the researcher, facilitator and note taker. Transcripts of the discussions were made anonymous by using participant codes. Data analysis followed the thematic content method, which involved identifying key categories and recurrent themes concerning infant feeding challenges. Three members of the research team (the facilitator, note taker and the researcher) reviewed the transcripts several times to become familiar with the content before the process of sorting, coding, and theme identification. Themes were developed independently again based on an inductive and deductive process of issues that emerged from the interviews by combining units of meaning relevant to the open- ended questions. These independently identified themes were subsequently compared before deciding on which to report on. A final list of themes was derived and applied to the data. The main discussion topics were, challenges of acquiring knowledge on appropriate infant feeding methods, challenges of exclusive breastfeeding, replacement feeding end early and abrupt cessation of breastfeeding. The main themes that emerged were: poor knowledge of the mothers on appropriate infant feeding methods, the high cost of infant formula by replacement feeding mothers hence its unaffordability, inability of the mothers to control the feeding due to the influence of the extended family and inability to produce sufficient milk for exclusively breastfeeding mothers. The major findings of the focus group discussions were summarized in a narrative report and key statements were listed according to topics. In presenting the data, relevant verbatim quotes were reported to aid in the interpretation of the data.

Information obtained from the completed questionnaires was cleaned, coded, entered and analyzed using SPSS version 16 computer software. Quantitative data was analyzed using descriptive statistics. Statistical procedures carried out included frequency distributions, percentages, means, and standard deviation to summarize observed variables. The results were presented using tables and textual summaries.

\section{Ethical considerations}

The study proposal was approved by the School of Graduate Studies Maseno University. Permission to conduct the study in Kariobangi health Centre was sought from the District Medical Officer of Health (DMOH) Nairobi North. Informed consent was obtained individually from each of the participants before being participating in the study. This was to ensure that participation was purely on a voluntary basis. Respondents were assured of confidentiality as serial numbers and not names were used to hide their identity.

\section{Limitations of the study}

The main limitation of the study was that the population studied represented Korogocho slums in which case the study may not be generalized to all HIV mothers outside Korogocho slums. 
Texila International Journal of Public Health

Volume 4, Issue 4, Dec 2016

\section{Results}

This chapter presents the results of the data obtained from the study on infant feeding challenges encountered by HIV positive mothers in Korogocho slums.

\section{Socio-demographic and economic characteristics of the study respondents}

Table 4.1 gives the socio-demographic and economic characteristics of the study respondents. The respondents' ages ranged from 18 to 37 years, with mean age of 25.3 years and a standard deviation of 4.93. The age of the infants ranged from six weeks to six months with a mean of 3.9 months and a standard deviation of 1.5. Most of the mothers 82(79.6\%) had more than one child with 21(20.4\%), 41(39.8\%), 27(26.2\%), 7(6.9\%), 6(5.8\%) and $1(0.9 \%)$ having one, two, three, four, five and eight children respectively. The number of children ranged from one to eight, with a mean number of 2.4. Many of the mothers 70(68\%) were married while 33(32\%) were single. Majority of the mothers $84(81.6 \%)$ either had no formal education at all $13(12.6 \%)$ or had only primary education71 $(69.0 \%)$ while $17(16.5 \%)$ had secondary education and 2(1.9\%) had tertiary education. Many respondents 52(50.5\%) were housewives, 28(27.2\%) did business and 20(19.4\%) were casual workers. Only 3(2.9\%) were in formal employment. Slightly more than half of the respondents 52(50.5\%) earned no income at all, 32(31.1\%) had a monthly income below two thousand shillings, 12(11.7\%) earned an income ranging from 2001 to $4000,3(2.9 \%)$ from 4001 to 6000 and 4(3.9\%) had an income ranging from 6001 to 8000 . For many respondents 53(51.5\%), husbands/ boyfriends were the main financial providers and decision makers far as use of available income was concerned followed by the mothers themselves 25(24.3\%), both husband and wife 19(18.4\%) and parents 6(5.8\%). Many 67(65.0\%) of the mothers resided in shacks, 29(28.2\%) in stone houses and 7(6.8\%) in prefabricated houses. Though a safe water supply is essential if artificial infant feeding is given to a baby only $9(8.7 \%)$ of the respondents had running water in their dwelling, 44(42.7\%) obtained water by buying, 32(31.1\%) from a tap outside their residence and $18(17.5 \%)$ used a communal tap. Only 26(25.2\%) of the respondents always boiled their drinking water, whereas $36(34.9 \%)$ added water guard and $41(39.8 \%)$ never treated their water. Many respondents 55(53.4\%) had no toilet with only 48(46.6\%) having a toilet at their place of residence. Majority $80(78 \%)$ of the respondents did not have electricity in their houses and their household waste was either dumped into a river 58(56.2\%) or disposed of in a communal waste dump 45(43.8\%).

Table 4.1 The study respondents' socio-demographic and economic characteristics

\begin{tabular}{|l|l|}
\hline Number of children & Number and percentage of respondents \\
\hline 1 & $21(20.4 \%)$ \\
\hline 2 & $41(39.8 \%)$ \\
\hline 3 & $27(26.2 \%)$ \\
\hline 4 & $7(6.9 \%)$ \\
\hline 5 & $6(5.8 \%)$ \\
\hline 8 & $1(0.9 \%)$ \\
\hline Level of education & \\
\hline None & $13(12.6 \%)$ \\
\hline Primary & $71(69.0 \%)$ \\
\hline Secondary & $17(16.5 \%)$ \\
\hline Tertiary & $2(1.9 \%)$ \\
\hline Occupation & \\
\hline Housewife & $52(50.5 \%)$ \\
\hline Business & $28(27.2 \%)$ \\
\hline Casual worker & $20(19.4 \%)$ \\
\hline Formal employment & $3(2.9 \%)$ \\
\hline Income (Kshs) & \\
\hline
\end{tabular}




\begin{tabular}{|l|l|}
\hline 0 & $52(50.5 \%)$ \\
\hline Less than 2000 & $32(31.1 \%)$ \\
\hline $2001-4000$ & $12(11.7 \%)$ \\
\hline $4001-6000$ & $3(2.9 \%)$ \\
\hline $6001-8000$ & $4(3.9 \%)$ \\
\hline Residential Houses & \\
\hline Shacks & $67(65.0 \%)$ \\
\hline Stone & $29(28.2 \%)$ \\
\hline Prefabricated & $7(6.8 \%)$ \\
\hline Sources of drinking water & \\
\hline Buys from vendor & $44(42.7 \%)$ \\
\hline Tap outside house & $32(31.1 \%)$ \\
\hline Communal tap & $18(17.5 \%)$ \\
\hline Tap in house & $9(8.7 \%)$ \\
\hline Human waste & \\
\hline Toilet absent & $55(53.4 \%)$ \\
\hline Toilet present & $48(46.6 \%)$ \\
\hline Household waste disposal & \\
\hline Dumped in river & $58(56.2 \%)$ \\
\hline Communal waste dump & $45(43.8 \%)$ \\
\hline
\end{tabular}

\subsection{Challenges of acquiring knowledge on appropriate infant feeding methods}

Table 4.2 Time of HIV test and areas of infant feeding counseling

\begin{tabular}{|l|l|}
\hline & Number and percentage of respondents \\
\hline Time of HIV test & \\
\hline During pregnancy & $90(87.4 \%)$ \\
\hline Before pregnancy & $13(12.6 \%)$ \\
\hline Area of counseling & \\
\hline Breastfeeding & $56(54.4) \%$ \\
\hline Replacement feeding & $55(53.4) \%$ \\
\hline Home hygiene & $8(7.8 \%)$ \\
\hline Early cessation of breastfeeding & $7(6.8 \%)$ \\
\hline Maternal nutrition & $2(1.9 \%)$ \\
\hline Feeding after breastfeeding cessation & $0(0 \%)$ \\
\hline Breast care & $0(0 \%)$ \\
\hline Good breastfeeding techniques & $0(0 \%)$ \\
\hline
\end{tabular}

Note: Numbers expressed are actual respondents. There were 103 respondents to all of the above factors.

Majority of the mothers 100 (97.1\%) reported having attended antenatal clinic. However, only $42(40.8 \%)$ attended more than three times, with $16(15.5 \%)$ attending only once, 25(24.3 \%) twice and 17(16.5\%) thrice. Most 90(87.4.1\%) of the mothers reported having had their HIV test during pregnancy with only $13(12.6 \%)$ having it before pregnancy. Table 4.2 gives the areas of income feeding counseling. Slightly more than half 56(54.4\%) of the mothers reported having been advised on breastfeeding, 55(53.4\%) on replacement feeding, 8(7.8\%) on home hygiene, 7(6.8\%) early cessation of breastfeeding and 2 (1.9\%) on maternal nutrition during breastfeeding. However, none received any counseling on feeding after breastfeeding cessation, maternal nutrition during breastfeeding or good breastfeeding techniques. Many mothers 57(55.3\%) said that they never fully understood the infant feeding counseling giving various reasons for not understanding with $40(38.8 \%)$ saying they received the counseling immediately after obtaining their HIV positive results, 23(22.3\%) the sessions were too short, $12(11.7 \%)$ sessions were too few and $9(8.7 \%)$ the counselor was unfriendly. 
Texila International Journal of Public Health

Volume 4, Issue 4, Dec 2016

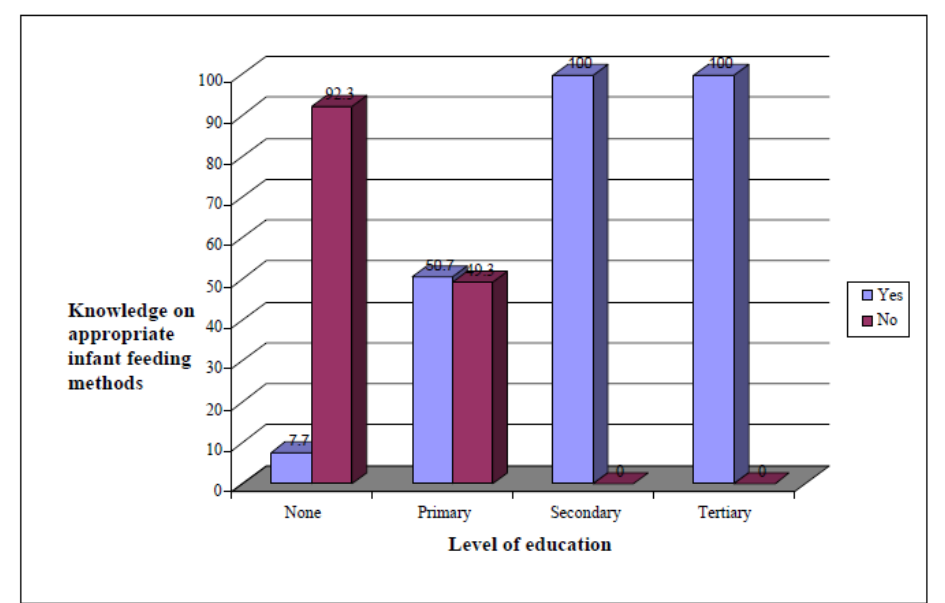

Figure 4.1 Association between respondent's level of education and knowledge on appropriate infant feeding methods

A mother's educational level seemed to have an influence on her understanding of infant feeding counseling as this understanding was higher among mothers with secondary/tertiary education as compared to those with none or only primary education (Figure 4.1).

Clinic attendance by the mothers had a direct influence on a mothers' knowledge on appropriate infant feeding methods. Mothers who attended more antenatal clinic visits had better knowledge on appropriate infant feeding methods compared to those with fewer visits (Figu4.2).

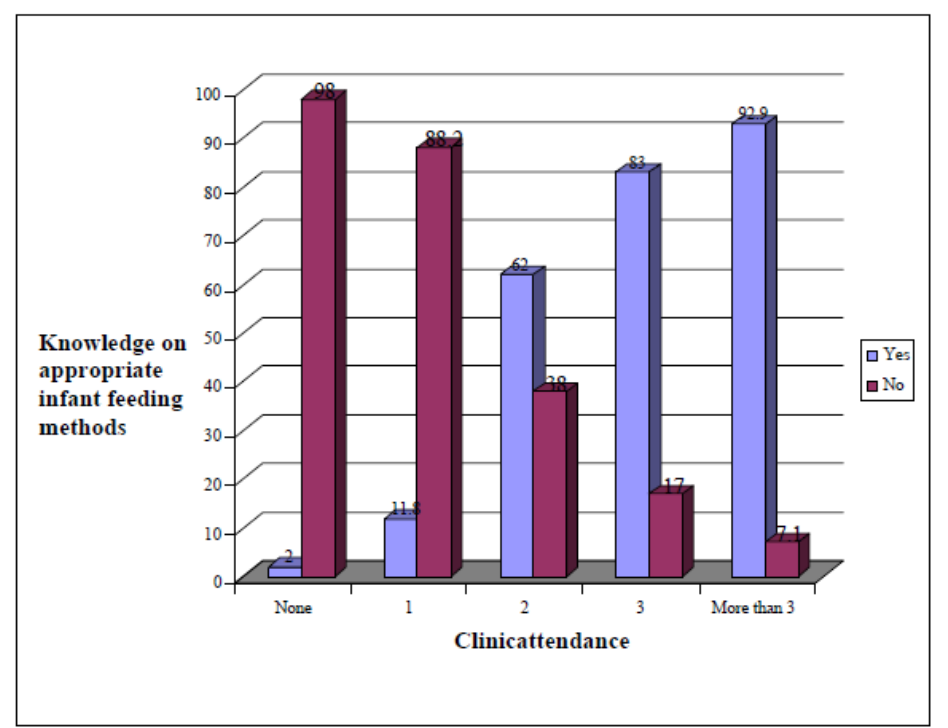

Figure 4.2 Association between mothers' number of clinic attendance and knowledge on appropriate infant feeding methods

These differences in understanding could be due to the fact that mothers with better education tended to attend clinic more times compared to those with less education. Also owing to the fact that they were better educated, they were probably at a better position to easily understand the counseling.

\section{Awareness of the mothers on MTCT of HIV through breastfeeding}

The mothers' awareness of MTCT of HIV was generally good among the study participants though some mothers had no idea at all about MTCT timing and prevention. Most mothers 80 (77.7\%) knew that HIV could be transmitted from mother to child. Knowledge of timing of MTCT was also quite high as 46 (44.7\%) knew it could be transmitted during pregnancy, 60 (58.3\%) during delivery and 63 (61.2\%) reported that HIV could be 
transmitted during breastfeeding. The mothers' knowledge on prevention of MTCT was also high as $56(54.3 \%)$ of the mothers knew it could be prevented through use of short course ARV drugs, 62(60.2\%) through exclusive breastfeeding, 60(58.3\%) through replacement feeding and 54(52.4\%) through early cessation of breastfeeding (Table 4.4). Though his knowledge was good, a number of mothers totally lacked knowledge on transmission during pregnancy 23(22.3\%), during delivery 26 (25.2\%) and during breastfeeding 25 (24.3\%) and also on prevention through exclusive breastfeeding13 (12.6\%), replacement feeding24 (23.3\%) and early and abrupt cessation of breastfeeding15 (14.6\%).

Table4.3 Mothers awareness on timing and prevention of MTCT (multiple responses)

\begin{tabular}{|l|c|c|c|}
\hline \multirow{2}{*}{ MTCT Timing } & \multicolumn{3}{|c|}{ Number (\%) of Respondents (N=103) } \\
\cline { 2 - 4 } & Yes & No & Don’t know \\
\hline During pregnancy & $46(44.7 \%)$ & $34(33 \%)$ & $23(22.3 \%)$ \\
\hline During delivery & $60(58.3 \%)$ & $17(16.5 \%)$ & $26(25.2 \%)$ \\
\hline During breastfeeding & $63(61.2 \%)$ & $15(14.6 \%)$ & $25(24.3 \%)$ \\
\hline MTCT prevention & & & \\
\hline Use of short course ARV drugs & $56(54.3 \%)$ & $23(22.3 \%$ & $24(23.3 \%)$ \\
\hline Exclusive breastfeeding & $62(60.2 \%)$ & $28(27.2 \%$ & $13(12.6 \%)$ \\
\hline Replacement feeding & $60(58.3 \%)$ & $19(18.4 \%$ & $24(23.3 \%)$ \\
\hline Early cessation of breastfeeding & $54(52.4 \%)$ & $34(33 \%$ & $15(14.6 \%)$ \\
\hline
\end{tabular}

A mother's education had a direct influence on her awareness on mother to child transmission of HIV through breastfeeding. The higher the mother's educational level, the better her awareness on mother to child transmission of HIV through breastfeeding. Awareness on MTCT of HIV was generally higher among the mothers with some secondary or tertiary education compared to those without any education at all or with only primary education (Figure 4.3).

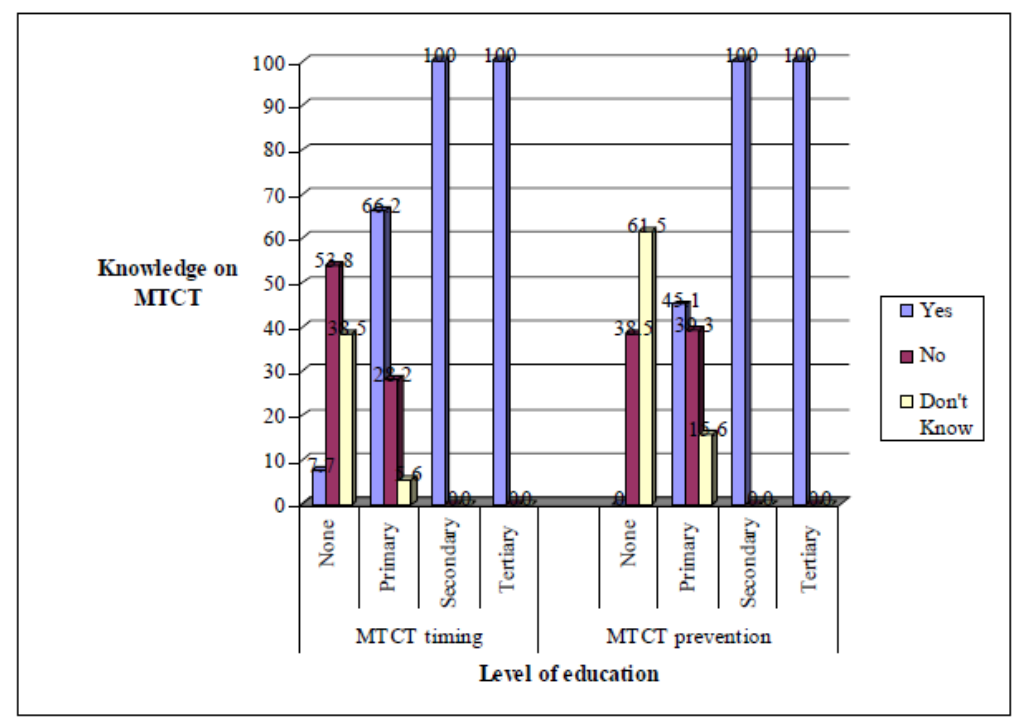

Figure 4.3 Association between respondent's level of education and knowledge on MTCT timing and prevention

Key: Yes-Mothers know that HIV can be transmitted from mother to child

No- Mothers know that HIV can't be transmitted from mother to child 
Texila International Journal of Public Health

Volume 4, Issue 4, Dec 2016

Don't know-These mothers don't know whether HIV can be transmitted from a mother to a child or not.

Antenatal clinic attendance was another major influence on a mother's awareness on mother to child transmission of HIV through breastfeeding. The higher the number of antenatal clinic visits, the better the awareness on mother to child transmission of HIV through breastfeeding (Figure 4.4).

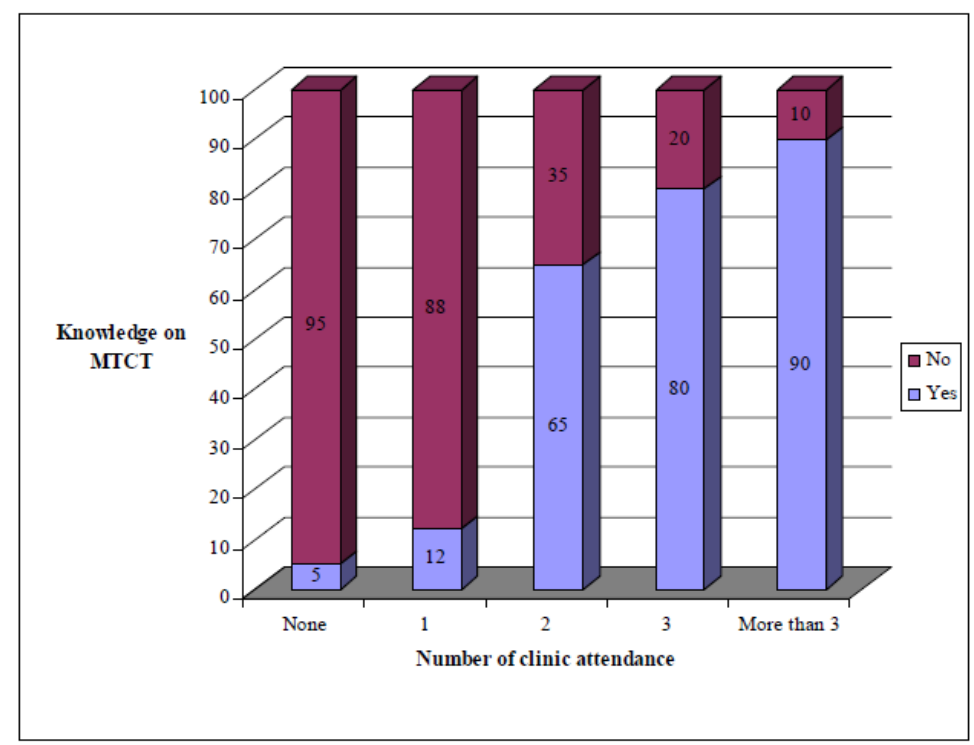

Figure 4.4 Association between mothers’ number of clinic attendance and knowledge on MTCT timing and prevention

Key

Yes -Mothers have knowledge on MTCT

No-Mothers have no knowledge on MTCT

\section{Challenges of exclusive breastfeeding and replacement feeding}

\section{Challenges of exclusive breastfeeding}

Table 4.2 gives the challenges encountered by the breastfeeding mothers. For majority of the breastfeeding mothers (29(56.9\%), failure to produce enough milk was reported as the greatest challenge.

"If you ask a mother to breastfeed exclusively, she will ask you how she will do it and yet she hasn't eaten. So even if you tell her to breastfeed, first of all that milk is not there because there is no food for to her to eat in the first place." (FGD, participant)

"Some of us don't have enough food to produce sufficient breast milk for the babies after two to three months. It is thus very hard to maintain exclusive breastfeeding of a baby at that age."(FGD, breastfeeding mothers)

Controlling the feeding was another major concern among 9(17.6\%) of the breastfeeding mothers because of the influence of other family members and some expressed fears of raising suspicion of HIV positive status $4(7.8 \%)$.

"In as much as one tries to breastfeed exclusively, there is this issue of relatives who want to give the baby other foods because they feel breast milk is not enough for the baby after the first few weeks. How can you stop them and what reason can you give them for not allowing other foods?" (FGD, breastfeeding mother).

Some mothers 6(11.8\%) too expressed concerns over the difficulties in maintaining exclusive breastfeeding because they had to go to work and so could not sustain exclusive breastfeeding 
"Sometimes it quite difficult to stay at home to take care of the baby because one must go to work so as to get your daily bread. If you just stay at home, how are you going to get food? Aren't you going to die of hunger?"(FGD, participant)

"We encounter so many problems. A mother cannot sit, caring for the young baby when she has other children to take care of. The other children will suffer. She has to go out and hustle for what they will eat. In this case she will stop to breastfeed since she cannot carry the baby to work. It is not our wish. It is just the way the situation is here in Korogocho." (FGD, participant)

For other mothers, infections in the baby's mouth 23(45.1\%) and breast infections 19(37.3\%) were great challenges that made their breastfeeding experiences difficult.

Table 4.4.1 Mothers' challenges with exclusive breastfeeding

\begin{tabular}{|l|l|l|}
\hline Exclusive breastfeeding & Frequency & Percent \\
\hline Failure to produce enough milk & 29 & 56.9 \\
\hline Infections in the baby's mouth & 23 & 45.1 \\
\hline Breast infections & 19 & 37.3 \\
\hline Inability to control the feeding & 9 & 17.6 \\
\hline Had to go work & 6 & 11.8 \\
\hline $\begin{array}{l}\text { Fears of raising suspicion of HIV positive } \\
\text { status }\end{array}$ & 4 & 7.8 \\
\hline
\end{tabular}

\subsubsection{Challenges of replacement feeding}

Table 4.4.2 Mothers' challenges with replacement feeding

\begin{tabular}{|l|l|l|}
\hline Replacement feeding & Frequency & Percent \\
\hline Feelings of guilty & 33 & 94.3 \\
\hline Could not afford replacement foods & 26 & 74.3 \\
\hline $\begin{array}{l}\text { Criticism from family, friends and } \\
\text { neighbours }\end{array}$ & 19 & 54.3 \\
\hline Accusations of promiscuity & 18 & 51.4 \\
\hline $\begin{array}{l}\text { Lack of fuel for replacement food } \\
\text { preparation }\end{array}$ & 17 & 48.6 \\
\hline Problems with replacement food preparation & 12 & 34.3 \\
\hline $\begin{array}{l}\text { Lack clean water for replacement food } \\
\text { preparation }\end{array}$ & 3 & 8.6 \\
\hline
\end{tabular}

Note: Mothers gave multiple responses. 35 mothers responded to questions on replacement feeding

Table 4.4 gives the challenges encountered by replacement feeding mothers. The most commonly expressed concern by the replacement feeding mothers was feelings of guilt for not breastfeeding that was reported by 33(94.3\%) of the mothers.

"Whenever you see other mothers breastfeeding their babies, you feel so guilty for not breastfeeding yours. Actually you always keep blaming yourself for all this especially when the baby is crying." (FGD participant, replacement feeding mother).

"I hate seeing my baby crying especially now that I can't soothe him with the breast. This makes me feel like I have neglected him and yet there is nothing I can do about it. I really hate myself for the whole thing. I actually don't know what to do."(FGD participant)

"My baby is not close to me at all because even when I leave her with someone, she never cries. She is actually not attached to me and this really hurts me." (FGD participant)

"My baby cries a lot and it is not easy to soothe him without the breast. I wish I could also breastfeed him as other mothers do. But now with this problem of mine, I don't even know what to do. It really makes me feel bad."(FGD, participant)

The various reasons given for feeling guilty were that they felt; they had neglected their babies14 (40.0\%), their babies were not close enough to them 21(60.0\%), they were to blame 
Texila International Journal of Public Health

Volume 4, Issue 4, Dec 2016

for being HIV positive 13(37.4\%), their babies were not healthy enough 8(22.9\%) and their babies cried a lot 22(62.9\%).

Inability to afford replacement food26(74.3\%), lack of fuel for replacement food preparation 17(48.6\%), problems with replacement food preparation12 (34.3\%) and lack of clean water for replacement food preparation $3(8.6 \%)$ were other major challenges among these mothers.

"It is really hard for most families to afford their own meals. But it is even harder to afford replacement food for the baby leave alone buying formula or milk until the baby is six months of age?"(FGD participant, replacement feeding mother)

Due to the high cost of infant formula, most replacement feeding mothers expressed that it was simply too hard for them to buy the amount of commercial infant formula necessary to feed their infants in a safe way with replacement foods. As a result, most of them 17(48.6\%) used milk from milk vendors, 15(42.9\%) used packet milk from the shops and only 3(8.6\%) used commercial infant formula whose supply was not sustainable. None of the mothers used powdered milk.

Criticism from family, friends and neighbours19 (54.3\%) and accusations of promiscuity 18(51.4\%) was also a commonly expressed concern among these mothers. Majority 23(65.7\%) of the replacement feeding mothers lacked support as family/friends were not in favor of them replacement feeding as only $12(34.3 \%)$ of the respondents had family /friends support.

\section{Challenges of early and abrupt cessation of breastfeeding}

Table 4.5 Mothers' challenges with early and abrupt cessation of breastfeeding

\begin{tabular}{|l|l|}
\hline Early and abrupt cessation of breastfeeding & $\begin{array}{l}\text { Number (\%) of respondents } \\
\text { N=17 }\end{array}$ \\
\hline $\begin{array}{l}\text { Lacked knowledge on replacement foods to } \\
\text { give }\end{array}$ & $15(88.2 \%)$ \\
\hline Lacked replacement foods to give & $13(76.5 \%)$ \\
\hline Had breast problems & $11(64.7 \%)$ \\
\hline Criticized by/ & \\
\hline Neighbours & $9(52.9 \%)$ \\
\hline Family members & $8(47.1 \%)$ \\
\hline Friends & $3(17.6 \%)$ \\
\hline
\end{tabular}

In this study, 17 (16.5\%) mothers had ceased breastfeeding early. Almost all these mothers 15(88.2\%) reported that they had not been given any advice on feeding after breastfeeding cessation and yet more than half of them 10 (58.8\%) had been advised to do so by the health workers.

"These nurses just tell you to stop breastfeeding but they are never concerned about how you feed your infant after that. You are just left to struggle alone and the way everything is expensive these days." (FGD, participant)

Some of these mothers therefore lacked sufficient replacement foods, knowledge on the proper replacement foods to give, and their preparation.

"Ever since I stopped breastfeeding my baby, his health has been deteriorating. I don't know which food to give him. How I wish I could get someone to advise me on what to feed him on." (FGD participant)

Criticism was a major concern for the mothers as $8(47.1 \%)$ were criticized by their family members about their decision to cease breastfeeding early, $3(17.6 \%)$ by their friends and $9(52.9 \%)$ by their neighbours. Breast problems were experienced by $11(64.7 \%)$ of the mothers. None of the mothers however knew how to handle these + problems.

"This issue of breastfeeding cessation is not as easy as I thought. My husband and other family members keep asking me why I stopped breastfeeding the baby but I have no answer to 
give them. It is such a problem to me and I really don't know how to go about it." (FGD, participant)

\section{Discussion}

This study has shown that HIV positive mothers in Korogocho slums are faced with multiple infant feeding challenges that makes it difficult for them to effectively follow the WHO guidelines on infant feeding.

\section{Challenges of acquiring knowledge on appropriate infant feeding methods}

Counseling HIV positive mothers so that they can make informed choices on safer infant feeding options is an important component of national programmes to prevent MTCT of HIV (WHO, 2003). Mothers need to know about the feeding options in order to assist them make better decisions on how best they can feed their infants (Desclaux et al., 2009). Findings from this study show that the knowledge of the mothers on appropriate infant feeding methods was inadequate for up to 74 (71.8\%) mothers reported that they never fully understood the infant feeding counseling. The greatest challenge to acquiring this knowledge was time of infant feeding counseling. Up to 40(38.8\%) mothers reported that their poor understanding of the counseling was because they received the counseling immediately after obtaining their HIV positive results. Leshabari and colleagues (2006) in their study in Tanzania reported similar results where the involved mothers reported that they did not feel adequately informed about HIV infant feeding and that the information was often given on the same day that they received their HIV test results. They found that mothers who chose replacement feeding after being counseled expressed uncertainty about preparing the formula or cow's milk. None received written instructions to take home. Poor antenatal clinic attendance among mothers in the current study was another major barrier to the acquisition of knowledge on appropriate infant feeding methods as this made their sessions too few $12(11.7 \%)$ and too short 23 (22.3\%). Inadequate infant feeding knowledge was also reported by De Paoli and colleagues (2004) in their qualitative study in Moshi, Kilimanjaro region investigating counselors' infant feeding advice to HIV-positive women. This study reported that infant feeding options were not accurately explained and that informed choice of infant feeding method, as recommended in the guidelines, was seriously compromised by inadequate information. Other studies in South Africa (Chopra et al., 2005, Shah et al., 2005), Brazil (Rea et al., 2007) also reported inadequate infant feeding knowledge among HIV positive mothers. In a study in South Africa more than half of the mothers interviewed said they never got information about infant feeding at antenatal clinic. In yet another study, it was found out that women did not understand what exclusive breastfeeding meant (Bland et al., 2002).

On the contrary, a study by Laar and Govender (2013) which evaluated HIV-positive women's knowledge following infant feeding counseling showed that the women demonstrated a good understanding of HIV transmission through breastfeeding and recommended infant feeding options. Another study conducted in Zambia which assessed the knowledge and understanding of HIV-positive mothers who had received pre and post-test HIV counseling of the WHO recommended infant feeding guideline reported that 35 percent of the women surveyed, understood the risk of transmission of HIV through breastfeeding (Aika, 2003). Another study conducted in Harare, Zimbabwe demonstrated that women's knowledge of HIV and infant feeding options had improved with increased exposure to counseling. Moreover, counseled mothers were 8.4 times more likely to uptake EBF than the mothers who were not exposed to counseling (Piwoz, 2005).

\section{Mothers awareness of MTCT through breastfeeding}

Most mothers in this study knew that HIV could be transmitted from HIV positive mothers to their children during pregnancy, delivery and breastfeeding. They also knew that MTCT could be prevented through exclusive breastfeeding, replacement feeding and early and abrupt cessation of breastfeeding. However about half of the mothers were not aware of the 
Texila International Journal of Public Health

Volume 4, Issue 4, Dec 2016

association between breastfeeding and HIV transmission and ways of preventing this transmission. Similar results were reported by Asefa and Beyene, (2013) who found that only $48.4 \%, 58.6 \%$ and $40.7 \%$ of the respondents knew of the possibility of MTCT during pregnancy, delivery and breastfeeding respectively. Contrasting results were however reported by Haddis and Jerene (2006) in their study in Ethiopia where they reported good knowledge of the mothers on the risk of transmission of HIV, peri-natally and through breastfeeding.

\section{Challenges of exclusive breastfeeding and replacement feeding}

\section{Challenges of exclusive breastfeeding}

The main difficulties reported by the breast-feeding mothers were, failure to produce enough milk, infections in the baby's mouth, breast infections, inability to control the feeding, the mothers had to go to work and fears of raising suspicion on their HIV positive status. Similar results were reported in a study in Malawi (Bezner-Kerr et al., 2007) which found that a major barrier in practicing exclusive breast-feeding was the perception of insufficient milk production as women sometimes doubted the feasibility of exclusive breastfeeding and were not convinced that a baby can grow healthy until the age of six months on breast milk alone. In Tanzania, HIV-positive mothers who were not able to do exclusive breast-feeding continued mix feeding since they believed their milk was not enough to make the baby grow 'fat and shiny' as expected by kin and neighbors (Leshabari etal., 2006). Arts and colleagues (2011) in their study in Mozambique found that Health care personnel had insufficient skills to offer remedies to deal with problems such as painful or cracked nipples, inflammation or perceived insufficient production of milk. Inability to control the feeding due to the influence of the extended family was also reported by $17 \%$ of the breastfeeding mothers in this study. A study which investigated infant feeding choices and experiences of HIV-positive mothers from two Ghanaian Districts, found social pressure and local norms as factors that influenced mothers' decisions to mix feed their children (Laar and Govender, 2013). A study Malawi gave similar results which showed that that babies' fathers and grandmothers were particularly influential regarding infant feeding and mixed feeding was found to begin within the first 48 hours after birth as advised by paternal grandmothers who are perceived to be key decision makers when it comes to good parenting (Bezner-Kerr et al., 2007). In a qualitative study in South Africa which examined infant feeding decision making and practices among HIV-positive women, it was found that key characteristics of women who achieved success in exclusivity (either in their breastfeeding or formula feeding) included the ability to resist pressure from the family to introduce other fluids and to recall key messages on MTCT risks and mixed feeding (Doherty et al., 2006b). Similarly, Omari and colleagues in their study in Zambia reported that HIV-positive women changed to mixed feeding although having started out with ERF. Once again, reasons included socio-cultural and expectations of family members (partners and mothers-in-law, extended families) and community members (Omari et al., 2003).

\section{Challenges of exclusive replacement feeding}

The challenges reported by the replacement feeding mothers were feelings of guilt, inability to afford replacement foods, criticism from family, friends and neighbours, accusations of promiscuity, lack of fuel for replacement food preparation, problems with replacement food preparation, lack clean water for replacement food preparation. Most mothers found it difficult to maintain replacement feeding because of the cost involved in maintaining it. Several studies have shown cost of replacement feeding as a major barrier to replacement feeding. A study in Kilimanjaro (Tanzania) on recommended replacement infant feeding options, reported that women considered formula as unaffordable but if the formula was distributed free of charge, the majority of them (82 percent) would choose this option (Laar and Govender, 2013). In a study in Uganda, it was reported that HIV-positive mothers started breastfeeding their babies once UNICEF stopped donating free infant formula, 
suggesting issues of cost (affordability) influencing their shift (Wendo, 2003). Similarly in South Africa, HIV-positive women opted for replacement feeding when formula milk was provided free. Moreover, women of lower socio-economic status found it difficult to continue formula feeding when there was an interruption in the supply of free formula (Doherty et al., 2006 b). Similar results were reported from Kenya

(Kiarie et al., 2004) and Nigeria (Sadoh et al., 2008). Besides the cost of formula, other socio-economic considerations including access to clean water and fuel for replacement food preparation, problems with replacement food preparation, electricity, and other infrastructure necessary for the safe and hygienic preparation of formula milk were reported by the mothers in this study. In the study in Nigeria, poor access to clean water for the preparation of formula milk was an important barrier to replacement feeding (Sadohet al., 2008). In South Africa, it was found that women who possessed a kettle, flask and electricity found it easier to feed their infants with formula milk during the night (Dohertyet al., 2006 a). Still in South Africa, in the province of KwaZulu Natal, it was reported that women who intended to use replacement feeding were more likely to have access to clean water and a regular income (Bland et al., 2002).

\section{Challenges of early and abrupt cessation of breastfeeding}

The longer an HIV positive mother breastfeeds the more likely she is to infect her baby. Up to $17(16.5 \%)$ of mothers in this study had ceased breastfeeding early. Among the mothers who had ceased breastfeeding early 15(88.2\%) said their main concern was lack of advice on how to feed their infants after breastfeeding cessation and yet most of them had been advised to do so by the health workers. Some of these mothers reported lack of replacement foods, lack of knowledge on the proper replacement foods to give and their preparation was reportedly poor among these mothers. Criticism was one major concern for the mothers as some were criticized by their family, friends and neighbors. Breast problems were also reported but none of the mothers reported having any knowledge on how to handle these problems. A study in Botswana evaluating infant feeding practices by mothers at PMTCT and non-PMTCT sites also found that very few mothers had received any advice about the cessation of breastfeeding or feeding after breastfeeding cessation (Shapiro et al., 2003). Similar findings were reported from a study in South Africa that found that a mother who did not breastfeed her infant would jeopardize her reputation as a 'good mother'. People would suspect that she had a lover or that she was HIV positive (Bland et al., 2002).

\section{Conclusion and recommendations}

\section{Conclusion}

1. The main challenge encountered by HIV positive mothers in acquiring knowledge on appropriate infant feeding methods was poor clinic attendance as it affects the time, duration and the number of counseling sessions.

2. Though there was some awareness on MTCT of HIV through breastfeeding, about half of the mothers were not aware of the association between breastfeeding and HIV transmission or its prevention.

3. The challenges encountered by breastfeeding mothers were inability to produce enough milk, infections in the baby's mouth and breast infections while replacement feeding mothers experienced feelings of guilt, inability to afford replacement foods, and criticism from both relatives and friends.

4. The main challenges encountered by HIV positive mothers who had ceased breastfeeding early were lack of advice on feeding after breastfeeding cessation and criticism from both relatives and friends.

\section{Recommendations}

1. More emphasis should be put on encouraging the mothers to start antenatal clinic attendance early at the recommended time. This will provide additional time for the 
Texila International Journal of Public Health

Volume 4, Issue 4, Dec 2016

health personnel to provide full information that will help in achieving empowered decision-making on appropriate infant feeding.

2. More effort should be put to enhance the mothers' awareness on the association between breastfeeding and MTCT of HIV transmission.

3. More detailed counseling to be done to the mothers on all aspects of breastfeeding and replacement feeding as this will help them solve the common infant feeding problems.

4. Provision of information on appropriate infant feeding practices after cessation of breastfeeding should be enhanced.

5. Further investigations are required to determine the cause of insufficient milk production by the mothers.

\section{References}

[1] Aidam BA, Pérez-Escamilla R, Lartey A. (2005) Lactation counseling increases exclusive breast-feeding rates in Ghana. Journal of Nutrition. 33: 1691-1695. jn.nutrition.org/content/135/7/1691.full

[2] Aika AAO, Luo C, Kankasa C, Bhat GJ, Bunn J. (2003) Infant-feeding practices of mothers of known HIV status in Lusaka, Zambia. Health Policy and Planning; 18: 156-162.)

[3] Alcala M. (2005) State of the world population. UNFPA Publication. New York, USA

[4] Asefa A, Beyene H. (2013) Awareness and knowledge on timing of mother-to-child

transmission of HIV among antenatal care attending women in Southern Ethiopia: a cross

sectional studyJournal of Reproductive Health10: 66

[5] Background. Korogocho Slum Upgrading Programme (KSUP http://www.ksup.org

[6] Becquet R, Ekouevi DK, Viho I, Sakarovitch C, Toure H, Castetbon K. (2005b). Acceptability of exclusive breast-feeding with early cessation to prevent HIV transmission through breast milk, ANRS 1201/1202 Ditrame Plus, Abidjan, Cote d'Ivoire. Journal of Acquired Immune Deficiency Syndrome, 40 (5): 600-608.

[7] Bezner KR, Dakishoni L, Shumba L, Msachi R, Chirwa M. (2008) "We grandmothers know plenty:" breastfeeding, complemantary feeding and the multifaceted role of grandmothers in Malawi. Soc. Sci. Med.66 (5):1095-105

[8] Bhandari N, Bahl R, Mazumdar S, Martines J, Black RE, Bhan MK.(2003). Effect of community-based promotion of exclusive breastfeeding on diarrhoeal illness and growth: a cluster randomized controlled trial. Lancet, 361 (9367): 1418-1423.

[9] Bland RM, Rollins NC, Coutsoudis A, and Coovadia HM. (2002). Breastfeeding practices in an area of high HIV prevalence in rural South Africa. Acta Paediatrica, 91 (6): 704-711.

[10] Burr C K. (2011) Reducing Maternal-Infant HIV

Transmission http://hab.hrsa.gov/deliverhivaidscare/clinicalguide11/cg-402_pmtct.html

[11] Chopra M, Doherty T, Jackson D, Ashworth A. (2005) Preventing HIV transmission to children: quality of counseling of mothers in South Africa. Journal of Paediatrics94: 357-363.

[12] Chopra M, Rollins N. (2007) Infant feeding in the time of HIV: Assessment of infant feeding policy and programs in four African countries scaling up prevention of mother to child transmission programs. Global Health Sciences Literature Digest. Available at:http://hivinsite.ucsf.edu/InSite?page=jl-20-02. Accessed September 15, 2013.

[13] Coutsoudis A, Pillay K, Kuhn L, Spooner E, Tsai WY, and Coovadia HM.(2001). Method of feeding and transmission of HIV-1 from mothers to children by 15 months of age: prospective cohort study from Durban, South Africa. AIDS, 15 (3): 379-387.

[14] Coutsoudis A. (2005). Infant feeding dilemmas created by HIV: South African experiences. Journal of Nutrition, 135 (4): 956-959.

[15] Desclaux A, Alfieri C. (2009) Counseling and choosing between infant-feeding options: Overall limits and local interpretations by health care providers and women living with HIV in resource-poor countries (Burkina Faso, Cambodia, Cameroon) Journal of Social Science and Medicine.30:203-210 
[16] De Paoli MM, Manongi R, and Klepp KI. (2001). Counsellor's perspectives on Antenatal HIV testing and infant feeding dilemmas facing women with HIV in northern Tanzania. Reproductive Health Matters, 10 (20): 144-156.

[17] De Paoli MM, Manongi R, Helsing E, and Klepp KI. (2002). Exclusive Breastfeeding in the era of AIDS. Journal of Human Lactation, 17 (4): 313-320.

[18] De Paoli MM, Manongi R, Klepp KI. (2004) Are infant feeding options that are recommended for mothers with HIV acceptable, feasible, affordable, sustainable and safe? Pregnant women's perspectives. Public Health Nutrition; 7: 611-619).

[19] Doherty T, Chopra M, Nkonki L, Jackson D, Persson L. (2006a) A Longitudinal Qualitative Study of Infant-Feeding Decision Making and Practices among HIV-Positive Women in South Africa. Journal of Nutrition; 136: 2421-2426

[20] Doherty T, Chopra M, Nkonki L, Jackson D, Greiner T. (2006 b) "Effect of the HIV epidemic on infant feeding in South Africa: "when they see me coming with the tins they laugh at me”. Bulletin of World Health Organisation; 84(2):90-96

[21] Ehrnst A, Zetterstrom R. (2005) Feeding practices of HIV-1-infected mothers: The role of counselors. Acta Paediatrica, 2005; 94: 263 - 265.)

[22] Emina J, Beguy D, Zulu EM, Ezeh AC, Muindi K, Elung'ata P, Otsola JK, Ye Y. (2009)

Monitoring of health and demographic outcomes in poor urban settlements: evidence from the Nairobi Urban Health and Demographic Surveillance System. Journal Urban Health 2011, 88(2):S200-S218.

[23] Engebretsen IMS, Moland KM, Nankunda J, Karamagi CA, TylleskärT, Tumwine JK. (2010) Gendered perceptions on infant feeding in Eastern Uganda: continued need for exclusive breastfeeding support International Breastfeeding Journal, 5:13 http://www.internationalbreastfeedingjournal.com/content/5/1/13

[24] Fawzi W, Msamanga G, Spiegelman D, Renjifo B, Bang H, Kapiga S. (2002). Transmission of HIV-1 through breastfeeding among women in Dar es Salaam, Tanzania. Journal of Acquired Immune Deficiency Syndrome, 31 (3): 331-338.

[25] GOK. (2009) Korogocho Slum Upgrading Programmehttp://www.ksup.org/

[26] Haddis M, Jerene D. (2006) Awareness of antenatal care clients on mother-to-child transmission (MTCT) of HIV infection and its prevention in Arba Minc Ethiopian Journal of Health

Development20(1):56-60 http://www.ajol.info/index.php/ejhd/article/view/10012

[27] Iliff, PJ, Piwoz EG, Tavengwa NV, Zunguza C, Marinda ET, Nathoo KJ. (2005). Early exclusive breast-feeding reduces the risk of postnatal HIV-1 transmission and increases HIV free survival. Journal of Acquired Immune Deficiency Syndrome, 19: 699-708.

[28] Kafulafula UK, Hutchinson MK, Gennaro S, Guttmacher S, Kumitawa A.(2013) Exclusive breastfeeding prenatal intentions among HIV-positive mothers in Blantyre, Malawi: a correlation study. BMC Pregnancy Childbirth. http://www.ncbi.nlm.nih.gov/pubmed/24195765

[29] Kiarie JN, Richardson BA, Mbori-Ngacha D, Nduati RW, John-Stewart GC. (2004) Infant feeding practices of women in a perinatal HIV-1 prevention study in Nairobi, Kenya. Journal of Acquired Immune Deficiency Syndrome, 35 (1): 75-81.

[30] Kimani-Murage EW, Kyobutungi C, Ezeh AC, Wekesah F, Wanjohi M, Muriuki P, Musoke RN, Norris SA, Griffiths P, Madise NJ. (2013) Effectiveness of personalized, home-based nutritional counseling on infant feeding practices, morbidity and nutritional outcomes among infants in Nairobi slums: study protocol for a cluster randomized controlled trial. Trials 2013, 14:445 http://www.trialsjournal.com/content/14/1/445

[31] Koniz-Booher P, Burkhalter B, deWagt A, Iliff P, Willumsen.(Eds) (2004). HIV and infant feeding. A compilation of programmatic evidence, Published for UNICEF and USAID by the Quality Assurance Project, University Research Co., LLC, Bethesda, MD.

[32] Korogocho. BEGA KWA BEGA Development project. Accessed 2009-06-02 http://www.begakwabega.com/Korogocho-eng.html

[33] Korogocho. St. John's sports society http://stjohnssportssociety.weebly.com/about-us.html

[34] Kuhn L, Stein Z, Susser M. (2004) Preventing mother-to-child transmission in the new millennium: the challenge of breast feeding. Paediatric and Perinatal Epidemiology, 18: 10-16. 
Texila International Journal of Public Health

Volume 4, Issue 4, Dec 2016

[35] Laar AS, Govender V. (2013) Individual and Community Perspectives, Attitudes, and Practices to Mother-to-Child-Transmission and Infant Feeding among HIV Mothers in Sub-Saharan Africa: A Systematic Literature Review. International Journal of MCH and AIDS2: 152-162

[36] Leroy V, KaronJM, Alioum A, Ekpini ER, van de Perre P, Greenberg AE.(2003) Postnatal transmission of HIV-1 after a maternal short-course zidovudine peripartum regimen in West Africa. AIDS, 17(10): 1493-1501.

[37] Leshabari SC, Koniz-Booher P, Astrom AN, De Paoli MM, Moland KM. (2006) Translating global recommendations on HIV and infant feeding to the local context: the development of culturally sensitive counseling tools in the Kilimanjaro Region, Tanzania. Implementation Science. 1:22 doi: 10.1186/1748-5908-1-22. Accessed January 1, 2013.

[38] Mnongya L M. (2013) Dilemma of choice between breastfeeding and replacement feeding among HIV positive mothers in Tanzania http://www.ajol.info/index.php/dmsj/article/view/88971

[39] Muluye D, Woldeyohannes D, Gizachew M, Tiruneh M. (2012) Infant feeding practice and associated factors of HIV positive mothers attending prevention of mother to child transmission and antiretroviral therapy clinics in Gondar Town health institutions, Northwest Ethiopia. BMC Public Health. 2012 Mar 26; 12:240. doi: 10.1186/1471-2458-12-240.

[40] Mugenda O, Mugenda A. (1999). Research Methods: Qualitative and Quantitative Approaches. Act Press, NBI.

[41] Nicolaj N. (2005) Korogocho the land and the people. Monthly Review Press Book, Nairobi

[42] Omari AA, Luo C, Kankasa C, Bhat GJ, and Bunn J. (2003) Infant-feeding practices of mothers of known HIV status in Lusaka, Zambia. Health Policy and Planning. 18 (2): 156-162.

[43] Piwoz EG, Bentley ME. (2005) Women's Voices, Women's Choices: The Challenge of Nutrition and HIV/AIDS135(4):933-7. http://www.ncbi.nlm.nih.gov/pubmed/15795465

[44] Rea MF, Gomes dos Santos R, Sanchez-Moreno CC. (2007) Quality of infant feeding counseling for HIV positive mothers in Brazil: Challenges and achievements. Acta Paediatrica; 96:9499.

[45] Rollins Meda N, Becquet R, Coutsoudis A, Humphrey J, Jeffrey B. (2004) Preventing postnatal transmission of HIV-1 through breast-feeding: modifying infant feeding practices. Journal of Acquired Immune Deficiency Syndrome, 35 (2):188-195.

[46] Sadoh E, Adeniran A, Abhulimhen-Iyoha I.(2008) Infant-feeding Practices among HIV-infected Mothers in an HIV-treatment Programme. Health Population and nutrition Journal. 2008; 26: 463-467.

[47] Shah S, Rollins NC, Bland RM. (2005) Breastfeeding knowledge among health workers in rural South Africa. Journal of Tropical Paediatrics, 51 (1):33-38

[48] Shapiro RL, Lockman S, Thior I, Stocking L, Kebaabetswe P, Wester C, Peter T, Marlink R, Essex M, and HeymannJ. (2003) Low adherence to recommended infant feeding strategies among HIV-infected women: results from the pilot phase of a randomized trial to prevent mother-to-child transmission in Botswana. AIDS Educationand Prevention, 15 (3): 221-230.

[49] Suryavanshi N, Jonnalagadda S, Erande AS, Sastry J, Pisal H, Bharucha KE, Shrotri Pandurang M, Bulakh PM, Phadke MA, Robert C, Bollinger RC, and Shankar AV. (2003) Infant Feeding Practices of HIV-Positive Mothers in India Journal of Nutrition 133:1326-1331

[50] Thairu LN, Pelto GH, Rollins NC, Bland RM, and Ntchangase N. (2005) Socio-cultural influences on infant feeding decisions among HIV-infected women in rural Kwa-Zulu Natal, South Africa. Maternal and Child Nutrition, 1: 2-10.

[51] UNAIDS. (2010) UNAIDS Report on the Global AIDS Epidemic 2010. Available at: http://www.unaids.org/en/dataanalysis/Accessed September 13, 2012.)

[52] UNAIDS. (2011) AIDS at 30;Nations at the crossroads. Section 3

http://www.unaids.org/en/media/unaids/contentassets/documents/unaidspublication/2011/20110531

[53] UNAIDS. (2012). Report on the Global AIDS Epidemic. Geneva: Joint United Nations Programme on HIV/AIDS

[54] UNAIDS. (2013) Report on the Global AIDS Epidemic. Geneva: Joint United Nations Programme on HIV/AIDS.

[55] UNICEF. (2012) Nutrition HIV and Infant Feeding 
http://www.unicef.org/nutrition/index_24827.html

[56] Wendo C. (2003) HIV-positive mothers in Uganda resort to breastfeeding. The Lancet; 16; 362 (9383) 542.)

[57] Wikipedia. (2013) Korogocho- Wikipedia, the free encyclopedia http://en.wikipedia.org/wiki/Korogocho

[58] WHO. (2003) UNICEF; UNFPA; UNAIDS. HIV and Infant Feeding: guidelines for Decisionmakers, Reviewed. Geneva, Switzerland World Health Organization

[59] WHO. (2006) WHO HIV and Infant Feeding Technical Consultation Held on behalf of the Interagency Task Team (IATT) on Prevention of HIV Infections in Pregnant Women, Mothers and their Infants: Geneva, Switzerland World Health Organization

[60] WHO. (2007) HIV Transmission through Breastfeeding. A Review of Available Evidence An Update from 2001 to 2007).

[61] WHO. (2011) WHO, UNAIDS and UNICEF. Towards universal access: scaling up priority HIV /AIDS interventions in the health sector. Progress report, 2011. Geneva, World Health Organization.

[62] Young SL, Mbuya NNM, Chantry JC. (2011) Current Knowledge and Future Research on Infant Feeding in the Context of HIV: Basic, Clinical, Behavioral, and Programmatic. Perspectives Advances in Nutrition.; 2: 225-243. 